\title{
Is a Significant Demographic Left Out of the Equation? An Overview of Possible Inequitable Access to Cybersecurity Educational Programs in the United States
}

\author{
Johanna Jacob \\ The University of Texas at San Antonio \\ johanna.jacob@utsa.edu
}

\author{
Gregory White \\ The University of Texas at San Antonio \\ Greg.White@utsa.edu
}

\begin{abstract}
Cybersecurity skills shortage has reached widespread proportions. The common consensus in the STEM community is there is a lack of an established pathway early on in K-12 education that would help students gain an interest in Cybersecurity and Cybersecurity related careers. Recent studies and national surveys indicate that most students are not well-informed about the educational and career requirements in the field. Though some cybersecurity education is offered in K-12 across the United States through various means such as camps, clubs, competitions and as standalone coursework, there is an uneven access for students to engage in these activities. Middle and high school student populations include teachers and educators who are part of smaller and lower income school districts which are often less exposed to the multifarious initiatives related to Cybersecurity. With the help of a case study, we present a preliminary analysis of the possible inequitable access to Cybersecurity education and propose a survey-based methodology to further this project.
\end{abstract}

\section{Introduction}

Cybersecurity is a critical and a rapidly growing avenue in which the demand for cybersecurity professionals far exceeds the number of qualified individuals. Recent data points out that the growing global demand for cybersecurity professionals will result in 3.5 million unfilled positions by 2021 . The U.S job cybersecurity growth rate is at $28 \%$, which is three times the national average of all occupations [1]. A global survey points out that 2300 security managers reported that $59 \%$ of their organization's security positions are vacant, although there is an $82 \%$ anticipated risk of cyberattacks to their infrastructure [1]. The increasing demand for cybersecurity professionals in both the private and the public sectors invokes a critical mission for educational institutions to attract and train the next generation cybersecurity workforce. In this regard, facilitating K-12 Cybersecurity Education plays a strategic role for government, academia, and industry in countering the shortage by creating awareness and providing students with the career pathways in cybersecurity they need early in the educational process. While the field itself has diversified with the inclusion of human factors, law, and business processes, it is troubling that disparities may exist to the access of cybersecurity resources in the education system that may be limiting the number and diversity of potential students.

\section{Related Work and Background}

According to the National Center for Education Statistics (NCES), "roughly half of all rural students in the U.S attend school in just 10 states, which includes some of the most populated urban states" [2]. A considerable number of rural school districts in some states across the United States are significantly smaller in comparison to the others. The Rural School and Community Trust, a national non-profit organization, indicates that at least half of the rural districts in 23 states enroll less than the national median enrollment for rural school districts [2].

Poverty concentration in the public-school setting poses a serious threat to the educational quality since they tend to be significantly underfunded and of low quality. According to "The Atlantic", a literary magazine, poorer school districts contribute to students with lower graduation rates [3]. Matthew Lynch states that, "While unemployment is a factor in poverty for some, there are many who are employed and still live below the poverty line. A higher level of education is needed for high paying jobs that can support a family. It is difficult to support a family with a minimum wage job, even when working full-time" [4]. This inequity gap is further diminished by the lack 
of funding for school districts. Lack of funding translates to a lack of quality educational resources, high qualified teachers, strong STEM programs and extracurricular opportunities that can help improve low-income students' educational achievements. A new survey from CYBER.ORG, administered by the EdWeek Research Center, deeply examined this knowledge gap [5]. According to their study, "lower levels of knowledge are reported among classroom teachers, in public schools, and in communities without cybersecurity resources such as cybersecurity companies, organizations that employ cybersecurity specialists, and universities that offer cybersecurity programs and/or conduct cybersecurity research" [5]. This disparity leads to creation of "cybersecurity deserts". "Cybersecurity deserts are zones where there is a significant disparity of access to programs and opportunities according to the socio-economic status of the intended population. This skill gap poses serious implications for adopting informed and knowledgeable cybersafe practices, which include anti-spyware, password practices, adequate privacy and sharing configurations, theft detection and prevention, and behaviors specific to online safety" [5]. With the current and impending demand for Cybersecurity professionals, the pathway to enter the cyber workforce has been eased. With some demonstrated capability, certification or even participation in a bootcamp, one can get into an entrylevel job in Cybersecurity [6]. According to ZipRecruiter, "The average annual wage for an Entry Level Cyber Security Analyst in the United States is $\$ 82,565$ for a year" [7]. Additionally, access to Cybersecurity Educational resources in the poorer school districts allows for upward socioeconomic mobility and paves way to more skilled, and higher paying jobs, thereby improving the livelihood of students in the poorer school districts. Equitable access to resources such as CyberPatriot, provides a path from high school to college and to the workforce, indeed.

In this regard, we aim to analyze and study the deterrents to an equitable access to Cybersecurity Education in the United States by considering CyberPatriot as a case study. The CyberPatriot National Youth Cyber Education Program is a globally acclaimed youth cyber education program that has been in existence since 2009. Created in the United States, its sole purpose and design is to inspire students towards careers in cybersecurity or other Science, Technology, Engineering and Mathematics (STEM) disciplines critical to our nation's future. In the 2018/19 season, there were 6,387 registered teams and over 32,000 competitors spanning thousands of schools across the United States [8]. The upward trend in registered teams continued in the 2019-2020 season with 6,760 teams, but with the challenges presented by the COVID-19 pandemic, registration dropped for the 2020-2021 season with 4,801 teams registering for the competition. Using the initial data provided by CyberPatriot, we provide an overview of the analysis of the participation demographics across all the states of the United States along with data obtained from the U.S Department of Education. We also point out some of the indicators that contribute to the significant trends that we observed from the participation metrics. Finally, we introduce a survey-based methodology that will be catered to the teachers, mentors and trainers of schools that participate in CyberPatriot to obtain more complete and current data to analyze more accurately student participation and interest, teacher training, public/private partnerships, demographics for schools and school districts, available STEM programs and in particular access to cybersecurity programs, and educator knowledge. The remainder of the paper is organized as follows. The preliminary analysis by regions and states is discussed in Section 3. Key observations and indicators are discussed in Section 4. The design of the survey instrument and its implications are discussed in Section 5 followed by Section 6 which is, Conclusion and Future Work.

\section{Preliminary Data Analysis}

One of the key factors that affects the disparity in access to quality cybersecurity education is the socioeconomic status of the student population in schools across the United States [2]. To understand this better, we analyzed the participation metrics of the CyberPatriot National Youth Cyber Education Program, co-founded by four organizations, and is run by the Air Force Association to inspire K-12 students towards careers in cybersecurity [8]. The competition puts high and middle school students in teams that are tasked with finding cybersecurity vulnerabilities within a simulated environment and hardening their systems while maintaining critical services. The competition is separated into three divisions. The Open Division is open to high school students from public and private school districts, scouting units, Boys and Girls clubs, home school and STEM programs [8]. The All-Service Division is specifically aimed at High school students in Junior Reserve Officer Training Corps (JROTC) programs, Civil Air Patrol Units and Naval Sea Cadet Corps Units. The Middle School division allows participation of middle school students from schools, scouting units and other programs aimed at this age group.

According to the data consolidated by the CyberPatriot foundation, 4801 teams participated in 
the competition in 2020-21 across all three divisions. Since 1950, the United States Census Bureau defines four statistical regions and is widely used for data collection and analysis. The divisions are Midwest, Northeast, West and South United States. The Northeast region encompasses the New England and the Middle Atlantic portions of the country. The Midwest region covers the East North Central and the West North Central states. The Southern region covers the South Atlantic, East South Central and West South-Central states Finally, the West region covers the Mountain and the Pacific portions of the country. Within the context of our study, we use the four broad regional divisions as defined by the U.S. Census Bureau, to organize the results of our analysis.

\subsection{Northeastern United States}

Figure 1 shows the participation range of CyberPatriot teams across the Northeast Region, specifically, Connecticut, Maine, Massachusetts, New Hampshire, New Jersey, New York, Pennsylvania, Rhode Island, and Vermont.

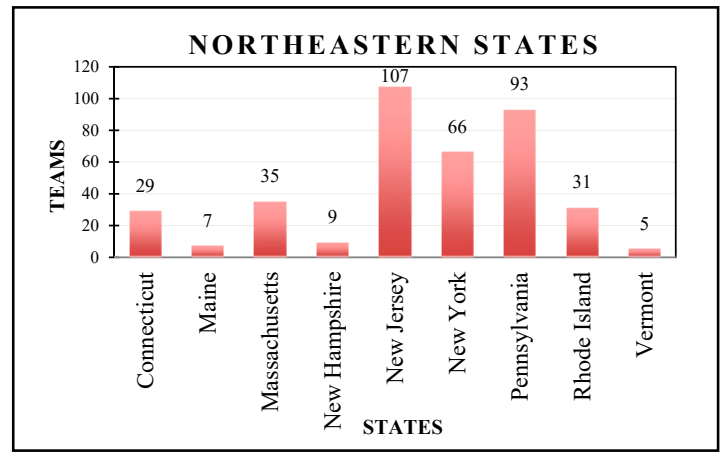

Figure 1. Participation of Northeastern States

From Figure 1, it is evident that New Jersey, New York, and Pennsylvania are the top three states in the Northeast region that have the highest participation in CyberPatriot. New Jersey and New York which constitute about 1.4 million and 1.1 million students respectively, have grown its cybersecurity job force by 80\% from 2010 to 2014 and are active players in cybersecurity education [9]. Together, New York and New Jersey have 18 schools that are recognized as NSA/DHS Centers of Academic Excellence [9]. To determine the relative income bracket that the school population fall into, we examined the number of registered schools that are categorized as Title I and those that are Non-Title I, and their respective participation in the CyberPatriot competition. Title I, also known as Part A (Title I) of the Elementary and Secondary Education Act, provides financial assistance to local educational agencies targeting students from low-income families to meet challenging state academic standards. This is more fully explained in Section 4.1.

Out of 2,493 operating schools in New Jersey, only 107 teams spanning 21 schools participated in the CyberPatriot competition. Of the 620 schools that have approved Title - I schoolwide programs, no single team was represented. In short, the representation of Title I schools in New Jersey in the CyberPatriot competition is non-existent. On the other hand, representation of Non - Title I schools is also relatively low. Out of the 1,873 schools that are not covered under the Title I schoolwide program, only 21 schools (representing 107 teams), participated in the competition. This constitutes only about $1.12 \%$ of Non - Title I schools. Although the overall participation of schools in New Jersey is only $0.8 \%$, as a percentage of the teams participating in the Northeast Region, New Jersey stands at $28.01 \%$, which is higher than the other states in the Northeastern region. Note that this percentage is based on the number of teams from the state as opposed to the number of schools participating. New York's overall participation is also low constituting 66 teams and comprising about $17.27 \%$ of all teams from the Northeastern States. The percentage of rural students in New Jersey is relatively lower compared to that of New York. While New York has a $11.2 \%$ rural student population, New Jersey comprises only $6.4 \%$ [2]. Though both states have differing rural student populations, their CyberPatriot participation metrics are not very different from each other. Out of the 987 schools in New York that are recognized as Title I, not one school was represented at the CyberPatriot competition. Out of the 879 schools that are not covered under the Title I schoolwide program, only 9 schools (representing 66 teams), participated in the competition. This means only about $1.02 \%$ of Non - Title I schools participated. Albeit the overall participation of schools is low, constituting only $0.4 \%$, the aggregate number of teams participating in CyberPatriot represented $17.27 \%$ of the teams from the Northeast Region and was third behind New Jersey and Pennsylvania. According to the Pennsylvania office of administration, the Commonwealth of Pennsylvania is marked as the leader among states in cybersecurity [10]. In the rankings of Ponemon Institutes' best schools for cybersecurity (sponsored by HP Enterprise Security), Pennsylvania houses three of the top ten schools for Cybersecurity namely Carnegie Mellon, University of Pittsburgh, and West Chester University of Pennsylvania [11]. The rural student population in Pennsylvania is the highest among the Northeastern states, constituting over a quarter of a million students 
and accounting for $17.3 \%$ of the total student population. However, in terms of CyberPatriot participation, there is no significant difference as compared to New York and New Jersey. This is evident from the fact that out of 1,240 schools that are approved to operate a schoolwide program, the representation of Title I schools is non-existent. All the 93 teams constituting 24 schools are representative of Non-Title I schools only. This denotes about $25.80 \%$ of CyberPatriot school participation in the Northeast Region. With large rural schools and districts [2], it is of interest that Pennsylvania's overall participation in CyberPatriot stands only at $1.9 \%$. In May 2015, the Rhode Island Cybersecurity Commission was established as a precursor to establish a sound foundation for information assurance, cyber hygiene, and statewide operational resiliency [12]. One of the core efforts of the commission was to amplify outreach and expand computer science offerings in high schools. For a comparatively smaller state, Rhode Island represents well above its weight class in the cybersecurity arena [13]. In accordance with the data presented, Rhode Island fielded 31 teams participating in CyberPatriot. Out of the 690 operating schools, only $2 \%$ of (spanning 31 teams) Non-Title I schools were represented. The representation of Title-I schools are once again non-existent. Their participation constitutes about $8.11 \%$ among the Northeastern State. It is also of interest to note that only $3.5 \%$ of Rhode Island students are enrolled in a rural district [2].

Massachusetts state and local education officials have seen growing interest in expanding K-12 Cybersecurity Education in the past quarter. With a growing economic edge, the Boston Metropolitan region reportedly represents about 80 percent of the state's economy, by housing 12 of the top Fortune 500 companies within its borders [13]. Several elite universities such as Harvard, Worcester Polytechnic and Northeastern are fully engaged in bringing the next generation of cybersecurity professionals to the marketplace through investment driven ventures with private and public entities [13]. However, out of the 400 schools that have approved Title - I schoolwide programs, there is no representation of these schools in CyberPatriot. The participation of Non-Title I schools stands at a slim figure of $1.04 \%$. The state has a relatively higher percent of rural student population numbering $8.5 \%$ in comparison to other NE states such as New Jersey and Rhode Island. The state ranks among the top 5 for wealthy rural communities and educational outcomes [2]. Acclaimed to have a small but a growing cybersecurity community [13], the state of New Hampshire has been developing guidance, such as HB1612 to combat cybercrime and educate its users [13]. The University of New Hampshire is the only school designated as a Center of Academic Excellence in Cyber Defense Education [13]. With CyberPatriot, the representation of Non-Title I schools stands at a slim figure of $0.86 \%$, with a total of 4 schools spanning 9 teams. Out of the 19 schools that are part of the Title-I program, no one school was represented. It is also of interest to note that over one third of all students in New Hampshire, about 34.3\%, are enrolled in a rural school district [2]. The state of Connecticut has been expanding its K-12 Cybersecurity educational efforts in the past decade. Since the inception of Connecticut's Computer Science Advisory Group in 2014, the state of Connecticut has assisted students in building relevant knowledge and skills. In 2018, the State Board Education adopted the CSTA K-12 Computer Science and ISTE standards and continue to work with partners to enhance certification of computer science teachers and endorsing cybersecurity initiatives as Girls Go CyberStart programs [14]. In terms of CyberPatriot, the participation of Title I schools stands unrepresented, just as the other states in the Northeastern region. The participation of Non-Title I schools is at a $1.53 \%$, with 29 teams represented by 10 schools. However, it is to be noted that Connecticut's rural district constitute only one in seven of the state's school and serves just under 55,000 students, which is a $11.0 \%$ overall [2]. It is one of the two states in the Northeastern region that caters to a lower percent of rural student population followed by Maine, whose rural student percent is at $8.3 \%$ [2]. Vermont is the smallest economic contributor in the United States [13] and with respect to K-12 Cybersecurity Education, is only in its developmental phases [13]. In 2018, the Governor of Vermont and the Vermont Agency of Education announced the start of a cybersecurity career pathway initiative that is working in close collaboration with employers, Career and Technical Education (CTE) centers, high schools, and colleges to create opportunities for students to adopt state-wide cybersecurity programs. Conclusively, Vermont continues to expand its reach in Cybersecurity based educational incentive programs. In accordance with the data, it is observed that Vermont and Maine have exhibited a slim participation of $1.31 \%$ and $1.83 \%$ respectively in the CyberPatriot competition with no representation from Title I schools. Though Vermont has nearly $55 \%$ of its student population attending school in a rural district, rural school communities are noted to be wealthy [2]. This is measured with the rural instructional expenditures per pupil that is at $\$ 7,449$ in Vermont [2].

Summarizing the participation from the Northeast Region, the overall participation of the Northeastern states in CyberPatriot stands at $7.9 \%$, with no 
participation from Title-I schools. Moreover, it is of concern that states such as Maine, Vermont and New Hampshire that have a relatively higher rural student population $(51.6 \%, 54.9 \%$ and $34.3 \%$ respectively) have not been represented well in the CyberPatriot competition. It is also of concern, that the states of Maine and Vermont have been ranked the highest in rural importance and are rated to be in a critical situation in terms of college readiness [2].

\subsection{Midwestern United States}

Figure 2 indicates the participation in CyberPatriot across the Midwestern region of United States namely Illinois, Indiana, Iowa, Kansas, Michigan, Minnesota, Missouri, Nebraska, North and South Dakota, Ohio, and Wisconsin. Michigan, Ohio, and Illinois are the top three states that have captured more than half of the participation from the Midwestern region.

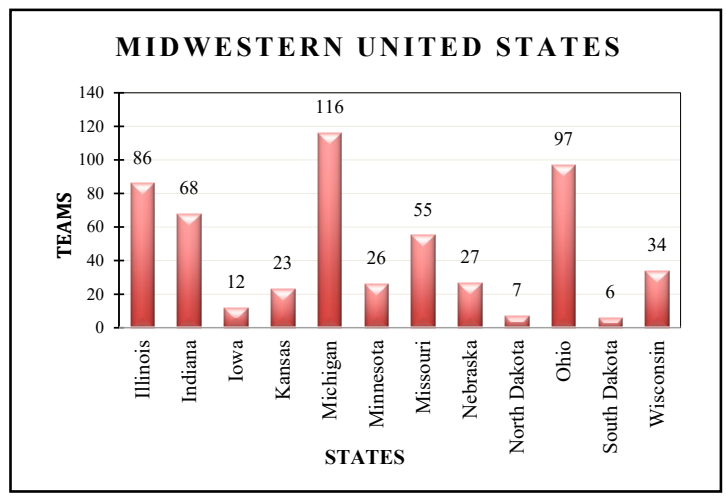

Figure 2. Participation Mid-Western States

Michigan is a smaller populous state as compared to New York with a population of 9.9 million people [2]. Established as an epicenter of automotive cybersecurity, the state of Michigan has cultivated cybersecurity talent through statewide education [13]. In this regard, the state of Michigan has the highest representation across the Midwest region in the CyberPatriot competition. Out of more than 3550 operating schools, 116 teams spanning a total of 37 schools, have represented the state of Michigan. This comprises about $20.82 \%$ of participation in the Midwestern region. The percent of Title-I participation is the lowest, about $0.2 \%$. Out of the 116 teams, only 19 teams spanning 7 Title-I schools participated. The rest of the 84 teams represented schools that were not under a Title-I schoolwide or a targeted assistance program. Out of more than 8000 operating schools, only 41 schools were represented. This number is of concern since $29.4 \%$ of all schools are rural, with nearly one quarter of a million students attending rural school districts. In short, Michigan's sizeable rural student population is vastly underrepresented in CyberPatriot.

The combined participation from Illinois and Ohio is $32.84 \%$ with 97 and 86 teams represented individually. While the states of Ohio and Illinois have a population larger than that of Michigan, with a total of more than 16000 operating schools, and initiatives such as the Ohio Cyber Range institute that are actively involved in K-12 Cybersecurity, their overall representation in the CyberPatriot is only $17.41 \%$ which is relatively on the underside. While Illinois has only $0.3 \%$ of Title-I schools represented, the state of Ohio has no Title I representation. It is also of interest to note that Ohio is the fourth largest in terms of rural student population after Texas, North Carolina, and Georgia, and is noted for its disproportionately less funding to rural districts [2].

Similarly, Indiana and Missouri fall under the same spectrum. Indiana represents around $12.20 \%$ whereas Missouri represents around $9.87 \%$ of the total participation in CyberPatriot from the Midwestern region. This is in retrospect of the fact that, Indiana has only recently established its cybersecurity landscape. Since 2018, Indiana has become committed to taking Cybersecurity to the next level by formulating a strategic framework as part of the Indiana Executive Council on Cybersecurity [15]. As part of the Cybersecurity strategic plan, the state of Indiana has advocated to increase K-12 Cybersecurity offerings through one or more cyber initiatives across 80 percent of schools. In this regard, the state of Indiana has strategized statewide cybersecurity [15]. While the state of Missouri has no representation from Title - I schools, Indiana constitutes of only $0.1 \%$ Title-I participation. With $24.6 \%$ rural students and ranked as one of the nation's top 10 largest states with the absolute rural student population, the state of Indiana is highly underrepresented. The percent of schools that participated in CyberPatriot in the states of Missouri and Indiana are only at $0.9 \%$ each, with a total of more than 10,000 operating schools together.

The other states in the Midwestern region fall under the lower tier. Nebraska, Minnesota, and Kansas have showed a lower overall representation of $4.84 \%$, $4.64 \%$ and $4.12 \%$. Out of the 1885 operating schools in Nebraska, 6031 schools in Minnesota, and 3312 schools in Kansas, not one Title-I school was represented. The percent of Non-Title I schools, on the other hand, is neither relatively high. While Nebraska has a 0.6 percent of Non-Title I schools participate, Minnesota and Kansas have 0.3 and 0.5 percent each. The state of Kansas has just started its statewide effort to push for Computer Science classes to be included in the core curriculum [16]. Iowa, North and South 
Dakota together represent only $4.48 \%$ of the CyberPatriot schools.

\subsection{Western United States}

The Western United States comprises Alaska, Arizona, California, Colorado, Hawaii, Idaho, Montana, Nevada, New Mexico, Oregon, Utah, Washington, and Wyoming. Figure 3 shows the range of participation in the Western states.

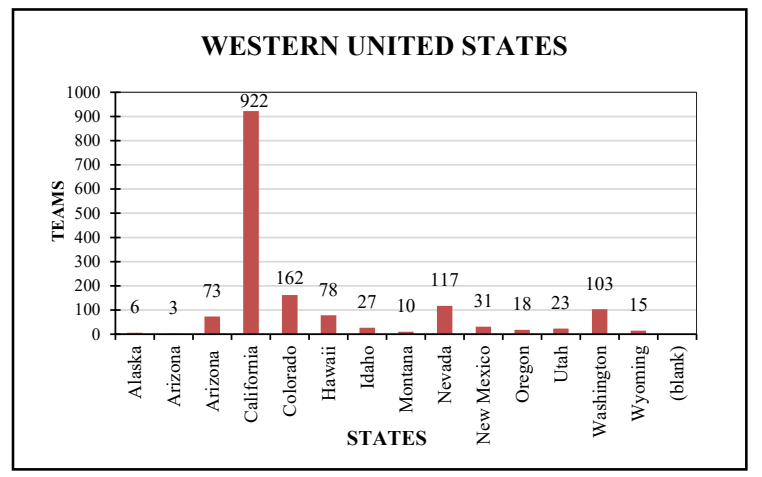

Figure 3. Participation of Western States

The second highest participation across the United States is represented by the Western states. California, the third largest state, included 922 of the 1588 teams that participated from the Western states. This comprises about $58.06 \%$. Consisting of a diverse population and a large geographical size, California has a critical public interest in closing the Cybersecurity Workforce and gap. This is strongly attributed to the California Cybersecurity Career Education Pipeline and Pathway Project (CCCEPPP) that was established in 2020 , whose sole aim is to increase state-wide cybersecurity program at all levels of education until the next decade $[9,18]$. It is also of interest that California has one of the nation's lowest rural schools and students. Around 50 of the 10,315 schools participated in the Open and Middle School categories and 17 schools participated in the AllService division. This altogether comprises about only $0.5 \%$ of schools in all of California. Though the rural student population in California is only $3.5 \%$ (as some of the Northeastern States), it is of significance that there is a relatively higher participation of Title I schools. 156 teams represented Title I schools which constitutes about $10 \%$ of schools in California. Colorado, Nevada, and Washington fall in the next lower tier of states in terms of their increased participation in CyberPatriot. Colorado claims to be a hotbed for cybersecurity development from 2016 with the launch of the National Cybersecurity Center which has been extensively propagating K-12 Cybersecurity Education through the NCC student alliance and the
Adult Education Initiative [13]. Nevada on the other hand has statewide Career and Technical Education standards for Cybersecurity with the development of a 3-course pathway in which students can receive security certifications [13]. Similarly, the state of Washington has a multi-threaded approach that uses governance mechanisms to bring together public, private, and academic institutions. In 2015, the Governor introduced that the Washington K-12 public school curriculum would include new Computer Science education standards. In accordance with the data provided by CyberPatriot, teams from Colorado, Nevada and Washington together constituted around $24.05 \%$ of the participation in the western region. Around 44 schools out of 1,825 schools represented Colorado, 22 of 664 schools represented Nevada, and around 25 of 2370 schools represented Washington.

These figures help understand that the total number of schools in a region is not the only underlying factor that determines an increase in participation in CyberPatriot. Hawaii and Arizona fall in the subsequent lower tier of CyberPatriot participation with a combined representation of 151 teams. Hawaii has only recently become a focal point for K-12 Cybersecurity education. In 2017, Hawaii joined the multi-state cybersecurity compact as a result of which educational initiatives in cybersecurity have increased. Hawaii has partnered with SANS to promote K-12 Cybersecurity through aptitude tests called Cyberstart [13]. In coordination with the Hawaii Departments of Education and Defense, University of Hawaii, and the Office of Enterprise Technology Services, SANS is onboard with the CyberStart Program that helps learn basic cybersecurity skills and test their cyber aptitude. Whereas in Arizona, cybersecurity activity dates back even to the beginning of 2000 with the Arizona Cyber Threat Response Alliance (ACTRA). Arizona State University has been propagating community cybersecurity by partnering with the Cybersecurity Education Consortium for K-12 Cybersecurity [13]. However, in accordance with the data, it is of stark interest that over 44 schools comprising 78 teams of the 287 operating schools represented Hawaii whereas only 20 of 4988 schools represented Arizona, contributing to only $0.4 \%$ of the total schools in the state. The rest of the states in the Western region fall in the lowest tier; Idaho with $1.7 \%$ and Alaska with $0.3 \%$ of participants from the West.

\subsection{Southern United States}

The Southern United States comprises Alabama, Arkansas, Delaware, District of Columbia, Florida, Georgia, Kentucky, Louisiana, Maryland, Mississippi, North Carolina, Oklahoma, South Carolina, 
Tennessee, Texas, Virginia, and West Virginia. Figure 4 represents the range of participation in the Southern states.

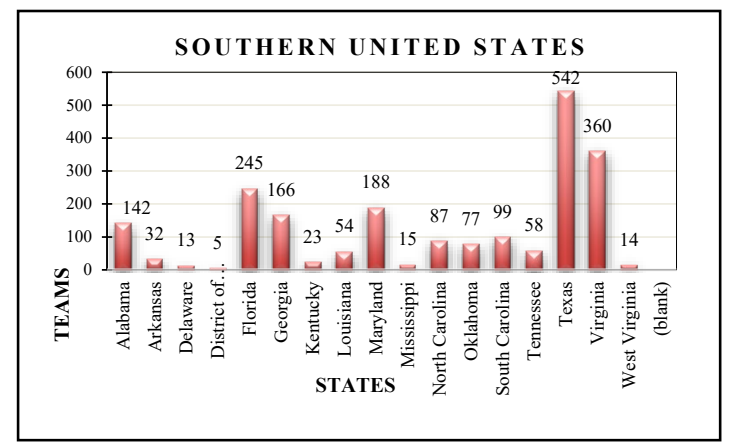

Figure 4. Participation of Southern States

"Texas is one of the strongest leaders for cyber development and continuation due to its digital infrastructure and economic advantages that has encouraged private and public partnerships to invest in this industry" [13]. As a result, Texas has a strong foothold both in terms of educational opportunities and economic foundations for Cybersecurity. Also, Texas houses more than 15 universities that are accredited to be Centers of Academic Excellence in Cyber Defense by the National Security Agency [9]. The University of Texas at San Antonio is rated as one of the topmost schools for cybersecurity education [17]. In terms of CyberPatriot participation, Texas constitutes about $25.5 \%$, spanning a total of 127 of the 9000 operating schools in the Open and Middle School division. This represents about $1.5 \%$ of all schools in the state, not including teams from the All Services division. Moreover, Texas has the nation's largest rural student enrollment, with nearly 700,000 students. Though the poverty level in rural school communities in Texas is at $277 \%$ and is ranked 28 of all states [2], rural graduation rates are high. A total of 542 teams, consisting of more than 2000 students from Texas, participated in CyberPatriot. Similarly, Virginia and Florida represent about $16.98 \%$ and $11.55 \%$ respectively. Florida, Virginia, Georgia, and Alabama have an established roadmap to Cybersecurity education in the K-12, post-secondary and in the higher educational institutions. While Florida is tied with Texas in housing the second highest number of CAE-CD accredited schools, Georgia emerges as an example of cyber governance with the creation of the Georgia Cyber Center and Cybersecurity Workforce Academy that strongly collaborate with educational agencies [13]. The Georgia Cyber Innovation and Training Center is a state-owned facility designed to promote modernization in cybersecurity through unique education, training, and research [19]. As for the size of Alabama, it shares the ranking of second highest in the nation for its overall rural education needs. According to NCES, nearly half of Alabama's schools are in rural communities and one in five of the state's students live in poverty and one in three students attends school in a rural district. Within the context of the participation numbers, it is of interest that of the 142 teams that represented Alabama, only 7 teams (spanning 4 schools) belong to schools that are designated as Title I. About $95 \%$ of student participation was from Non-Title I institutions. This trend is seen in the top 5 southern states wherein the highest number of teams were students that were enrolled in Non-Title I schools. Figure 5 presents a graphical representation of the same.

The subsequent tier of states whose overall participation lies between 2 and $4 \%$ are North Carolina, Oklahoma, South Carolina, Tennessee, and Louisiana. The state government of North Carolina has been an active proponent of the cybersecurity industry. Organizations such as Girls GoCyberSmart, CyberVetsUSA and North Carolina Center for Cybersecurity facilitate effective communication between industry, academia, and government institutions [13].

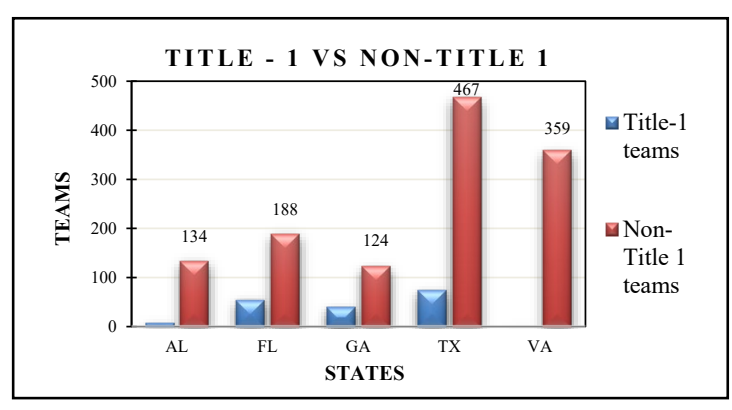

Figure 5. Title I Versus Non-Title 1

In terms of CyberPatriot participation, $\mathrm{NC}$ has a total of 87 teams spanning 48 schools out of which no schools are designated as Title I. With more than half a million students enrolled in NC's rural school districts, it is concerning that rural student population have no participation in a National program as CyberPatriot. This trend is seen to decline further in other states of the same tier. Only 10 of 99 teams in South Carolina, 2 of 77 teams in Oklahoma, 1 of 58 teams in Tennessee and 1 of 54 teams in Louisiana identify as enrolled in a Title I school. According to NCES, South Carolina's rural school districts have some of the nation's highest rate of enrollment for students of color [2]. The results of this preliminary analysis help understand there is a significant disparity in the participation of schools across states in a National Youth Cyber Competition that has been 
conducting its competitions since 2009. While the participation of Title I schools is dismal across states and regions, states that are highly populated with rural students are represented significantly. A deeper analysis indicates that there is less than $3 \%$ of overall students in the South that are from low-income and poor communities represented by Title I. Following the initial analysis of the data presented by CyberPatriot, we identified the following factors may potentially contribute to the disparity in Cybersecurity resources across the United States.

\section{Key Observations and Indicators}

\subsection{Low Participation of Title I Schools}

Title 1, also known as Part A (Title 1) of the Elementary and Secondary Education Act, provides financial assistance to local educational agencies targeting students from low-income families meet challenging state academic standards. The majority of the Title I fund are allocated at the district level in all states. Usually, Title I grants are allocated through four different grants - namely, Basic Grants, Concentration Grants, Targeted Grants, and Education Finance Incentive Grants (EFIG). According to the U.S Department of Education, National Center for Education Statistics, school districts that had a higher number of poorest districts had the highest total Title 1 allocations per formula-eligible child and the least poor districts received the lowest total Title 1 allocations per child. Title I funds are also part of the Small, Rural School Achievement Programs that provide rural Local Education Agencies and Schools to fund initiatives aimed at improving student achievement [2]. In this regard, we want to study the inter-relationship between rural schools that receive statewide assistance and their participation in CyberPatriot. Rural schools in Delaware, Hawaii and Nevada are ranked as some of the lowest in the United State in NAEP scores. Delaware is one of the least rural states in the country, but the student population is one of the most racially diverse of any state in the U.S. Despite low poverty rates, higher teacher salaries and instructional spending that is above average, Delaware's rural schools tend to be in communities that are poorer than average and results in lower scores [2]. Though $82 \%$ of student population in Delaware attend Title I schools, there is a sparse representation in STEM related engagement. In the case of CyberPatriot participation, it is observed that only 3 of the 214 operating schools in Delaware participated in the competition. However, a similar trend with Nevada is observed to be otherwise. Nevada's rural student population is also small with a total of 7,500 students and is observed to be the most diverse in the nation in terms of race, socioeconomic status, and geographic mobility. In comparison with Delaware, they receive only $3.3 \%$ of federal education funds for the rural school districts. Though only $18.6 \%$ of Nevada's students attend Title I school, there is an increased participation in CyberPatriot participation. 117 teams spanning 23 schools participated in the contest.

According to the U.S Department of Education, over 7 million students are enrolled in rural school districts and nearly one sixth of those rural students live below the poverty line [2]. This specific case may allow us to propose that there are outliers to the common observation that districts which receive increased federal funds also have better student engagement in Cybersecurity. It may also imply that rural student populations become invisible to potential opportunities in Cybersecurity Educational initiatives because of the highly visible and overarching urban population in the state, disproportionate allocation of Title I funds and diversity of the constituting student population. However, within the scope of CyberPatriot participation data, the above statements cannot be objectified and demands further research and extensive data gathering across participating schools and school districts. With the onset of our surveybased methodology, we intend to analyze, define, and gauge some primary indicators for student engagement and interest in Cybersecurity based educational initiatives.

\subsection{Public/Private Partnerships and Demand for Trained Teachers}

A ubiquitous professional field such as Cybersecurity that touches many different industry sectors and occupational groups requires collaboration and information sharing between the public, private and educational communities to foster interest and help understand portable skills that can be linked to education programs such as CyberPatriot [10]. Although there is no centralized and documented data to statistically understand the correlation between educational outcomes and public/private partnerships, we comparatively analyze the growth of Cybersecurity education in two different states based on historical data. In addition, the achievement to meet demands of increased Cybersecurity based educational programs requires professional teachers and educators who have feasible access to build and access content relevant to security. A recent study reports that 62 percent of educators they surveyed say they know a lot or some about cybersecurity whereas only 40 percent say the 
same of their students, indicating that student and educator knowledge of cybersecurity are correlated [5]. According to NCES, rural school districts are simply at a disadvantage regarding recruiting teachers with competitive technical skills and training due to many factors, but lower teacher salaries (technically known as Adjusted Rural Salary Expenditures) are one among them [2]. The other factors include inadequate funding, lack of amenities, social and geographic isolation, and limited access to professional development opportunities. The report also indicates that states in the Southeast, Southwest and Midwest regions such as Kansas, Arkansas, Oklahoma, Missouri, Mississippi, North Dakota, South Dakota, Colorado, Arizona, and Tennessee have lower teacher salaries as opposed to states in the Northeast and West such as New Jersey, New Hampshire, Delaware, California, Pennsylvania, Nevada, Massachusetts, and New York, which have the highest teacher salaries. However, the relationship between rural salary expenditures and CyberPatriot participation is yet to be studied.

\section{Methodology and Survey Design}

In this paper, we present a survey-based methodology to help understand the perspectives of teachers and educators across the United States on the posture of access to Cybersecurity Educational Resources in their respective schools and community. We developed this survey based on the lack of literature that identifies specific challenges that the survey aims to explore. In this section, we present the structure of our online survey named "Towards an Equitable Access to Cybersecurity Education in the United States" (Please refer to the appendix). The goal of the survey is to establish a baseline understanding of the access to cybersecurity based educational resources across schools in the United States and to see how disparities may be part of this

The research questions that propel the study are as follows: 1. Is there a general interest and engagement from schools participating in the Title -1 program towards Cybersecurity Education? 2. Is there a general interest and engagement from schools that are not covered in the Title I program? 3. Is there a relationship between the demographics of student population within school districts and engagement in Cybersecurity education? 4. Is there a dearth in Cybersecurity knowledge among the educators in the United States? 5. How is Cybersecurity Education propagated among the schools? 6 . Is there a relationship between the strong presence of cybersecurity companies in the community and increased interest to learn cybersecurity? 7. Are students in the "lower", "smaller" rural districts significantly less exposed to opportunities to learn and engage in Cybersecurity based educational activities?

The motivation behind the above research questions are to: 1. Understand factors and identify barriers that are attributable to learn or engage in Cybersecurity related activities.2. Understand the economic posture and demographics of the student population/school district that participate in CyberPatriot.3. Understand the relationship between Title I and Non-Title I schools, and CyberPatriot. 4. Understand the relationship between Title I schools and STEM engagement, in general. 5. Understand the relationship between presence of cybersecurity companies in the community and increased interest in STEM/Cybersecurity. In accordance with the research questions and the motivation behind each of them, the following methodology was used to design the survey: 1. A literature review was conducted along with preliminary analysis that ensures the relevance and relatability of this survey. 2. A survey that gathers information relevant to demographics and perspectives of the above-mentioned research questions is designed. 3. Approval has been obtained from the Institutional Review Board of the University of Texas at San Antonio restricting the survey from recording any participant information or behavior and claiming that it does not pose any risk or harm to the subjects other than those encountered in everyday life. 4. The survey will be provided to thousands of teachers, mentors and administrators of schools that participate in CyberPatriot through the help of the CyberPatriot program office. 5. Obtained data will be automatically reported in the survey system for further analysis. 6. Collected data will be analyzed using statistical probability and quantitative analysis tools as $\mathrm{R}$ and SPSS. The survey went through multiple drafts and was reviewed by experts in the field to fine tune wording, content, and format. The survey consists of 20 questions which include 2 free response questions and 18 multiple choice questions. Our intended participants for this survey are teachers, mentors, administrators, or officials of schools that participate in CyberPatriot that are over 18 years of age that necessarily have a background in security. According to IRB policies, participants are not compelled to answer any single question. The online survey has been disseminated and will be open for a span of two to three months up until the time when CyberPatriot registrations for 2021-22 will be closed.

\section{Conclusion and Future Work}

There are many barriers and limitations with the current Cyber Workforce development and education 
- inequitable access to Cybersecurity Educational programs is one of them. The preliminary observations made in this report, help understand that there is an unequal access across schools and school districts in their CyberPatriot participation. While Northeastern and Midwestern regions have shown less than one fourth of the total participation, the Southern states have shown $44.15 \%$, and the Western states denote a $33 \%$. Regions with an established K-12 roadmap, with universities and organizations that employ or offer cybersecurity programs and outreach, have a relatively upraised participation. However, the results of the study are not conclusive due to various factors that influence them - the percent of Title - I schools in rural districts, the nature of the Title - I grant allotted to districts - whether Targeted or Schoolwide, and if they have a cybersecurity-based program connected to it, and the digital gap that exists among students. Results of the survey will help understand the above key factors along with the challenges presented for rural schooling, thereby, suggesting urgent and comprehensive needs to boost student interest, and pave the way for substantial growth in Cybersecurity Education in the K-12 avenue across the United States.

\section{References}

[1] M. Calam, D. Chinn, J. F. Porter, and J. Noble, "Perspectives on transforming cybersecurity," McKinsey Glob. Inst., no. March 2019, [Online]. Available: https://www.mckinsey.com/ /media/McKinsey/McKinsey Solutions/Cyber Solutions/Perspectives on transforming cybersecurity/Transforming

cybersecurity_March2019.ashx.

[2] D. Showalter, S. L. Hartman, J. Johnson, and B. Klein, "Why rural matters 2018-2019," no. November, pp. 1-153, 2019, [Online]. Available: http://www.ruraledu.org/WhyRuralMatters.pdf.

[3]. A. Semuels, "Good School, Rich School; Bad School, Poor School," The Atlantic, 13-Jun-2021. [Online]. Available:

https://www.theatlantic.com/business/archive/2016/08/prop erty-taxes-and-unequal-schools/497333/. [Accessed: 15Jun-2021].

[4] A. Education et al., "Poverty and School Funding: Why Low-Income Students Often Suffer - The Edvocate", The Edvocate, 2021. [Online]. Available: https://www.theedadvocate.org/poverty-and-schoolfunding-why-low-income-students-often-suffer/.

[Accessed: 15- Jun- 2021].

[5] "3 Ways To Land a Cybersecurity Job Without a Degree", Springboard.com, 2021. [Online]. Available: https://www.springboard.com/library/cybersecurity/how-toget-a-job-without-a-degree/. [Accessed: 15- Jun- 2021].

[6] A. Education et al., "Poverty and School Funding: Why Low-Income Students Often Suffer - The Edvocate", The Edvocate, 2021. [Online]. Available: https://www.theedadvocate.org/poverty-and-school- funding-why-low-income-students-often-suffer/.

[Accessed: 15- Jun- 2021].

[7] "ZipRecruiter" [Online]. Available: https://www.ziprecruiter.com/Salaries/Entry-Level-CyberSecurity-Analyst-Salary. [Accessed: 15- Jun- 2021].

[8] Northrop Grumman, "AFA CyberPatriot Website." 2019, [Online]. Available: https://www.uscyberpatriot.org/. [9] "CAE Institution Map | CAE in Cybersecurity Community", Caecommunity.org, 2021. [Online]. Available: https://www.caecommunity.org/cae-institutionmap. [Accessed: 15- Jun- 2021].

[10] "Cybersecurity", An Official Pennsylvania Government Website, 2021. [Online]. Available: https://www.oa.pa.gov/Programs/Information\%20Technolo gy/cybersecurity/Pages/default.aspx. [Accessed: 10- Jun2021].

[11] "Best Schools for Cybersecurity", www.hp.com/hpinfo/newsroom, 2014. [Online]. Available: http://www.hp.com/hpinfo/newsroom/press_kits/2014/RSA Conference2014/Ponemon_2014_Best_Schools_Report.pdf . [Accessed: 10- Jun- 2021].

[12] "A Framework for the Development of Cyber Protection", https://www.governor.ri.gov, 2015. [Online]. Available:

https://governor.ri.gov/documents/press/RICybersecurityCo mmissionOctober2015Report.pdf. [Accessed: 05- Jun2021].

[13]"Cybersecurity Degree Programs by State", Cybersecurity guide. [Online]. Available: https://cybersecurityguide.org/states/. [Accessed: 05- Jun2021].

[14] "Governor Lamont Encourages Connecticut High School Students to Participate in Cybersecurity Competition", State of Connecticut, 2019. [Online]. Available: http://Governor Lamont Encourages Connecticut High School Students to Participate in Cybersecurity Competition. [Accessed: 05- Jun- 2021].

[15]"Indiana Cybersecurity Strategic Plan", Cybersecurity Report, 2018. [Online]. Available: https://www.in.gov/cybersecurity/files/Cybersecurity-

Report-FINAL-Full-Report1.pdf. [Accessed: 14- May2021].

[16] "Rural computer science program goes statewide in Kansas," Govtech.com, 03-May-2021. [Online]. Available: https://www.govtech.com/education/k-12/rural-computerscience-program-goes-statewide-in-kansas. [Accessed: 15Jun-2021].

[17] Usnews.com. [Online]. Available: https://www.usnews.com/best-colleges. [Accessed: 15-Jun2021].

[18] C. Cybersecurity, T. Force, W. Development, and E. Subcommittee, "California Cybersecurity Workforce Development and Education Strategy (2020-2030): Framework and Recommendations for a California Cybersecurity Career Education Pipeline and Pathway Project (CCCEPPP )," 2020.

[19] C. Keyser, "New Hampshire: It's time to talk about HB 1612," Security7.net. [Online]. Available: https://www.security7.net/news/what-is-hb-1612.

[Accessed: 15-Jun-2021] 


\section{APPENDIX}

\section{Survey: Towards an Equitable Access to Cybersecurity Education in the United States}

Welcome to the research study! We are interested in understanding the Inequitable Access to Cybersecurity Education across schools in the United States. You will be presented with information relevant to the same and asked to answer some questions about it. Please be assured that your responses will be kept completely confidential.

Your participation in this survey is voluntary. You may refuse to take part in the research or exit the survey at any time without penalty. You are free to decline to answer any question you do not wish to answer for any reason. The study should take you 2 5 minutes to complete. You will receive no direct benefits from participating in this research study. However, your responses may help us learn more about the various factors and detriments that contribute to understanding the broad spectrum of access to Cybersecurity Educational resources across the United States.

Our research records will not be released without your consent unless required by law or a court order. Your records may be viewed by the Institutional Review Board, but the confidentiality of your records will be protected to the extent permitted by law. The data resulting from your participation may be used in publications and/or presentations but your identity will not be disclosed.

There are no foreseeable risks involved in participating in this study other than those encountered in day-to-day life. Your survey answers will be sent to a link at Qualtrics where data will be stored in a password protected electronic format. Qualtrics does not collect any identifying information such as your name, email address, or IP address. Your responses will remain anonymous. No one will be able to identify you or your answers, and no one will know whether you participated in the survey. If you would like to contact the Principal Investigator in the study to discuss this research, please e-mail Johanna Jacob at johanna.jacob@utsa.edu. This research is being overseen by an Institutional Review Board ("IRB"). You may also talk to them at IRB@utsa.edu if you have questions regarding your rights as a research participant or other questions, concerns, or complaints.

By clicking the button below, you acknowledge that your participation in the study is voluntary, you are 18 years of age, and that you are aware that you may choose to terminate your participation in the study at any time and for any reason. Please note that this survey will be best displayed on a laptop or desktop computer. Some features may be less compatible for use on a mobile device.

- I consent, begin the study

- I do not consent, I do not wish to participate

Q1 In which state do you currently reside?

Q2 In which of the following categories do you identify yourself?

- Teacher

- Mentor

- Administrator

- Other

Q3 In which of the following categories do you work?

- Public School/District

- Private School/Network

- Other

Q4 What is the name of your school?

Q5 In which of the following categories would you best describe your district based on the economic advantages presented to the student population?

- Upper

- Middle

- Lower

Q6 The population size of your community is in one of the following ranges,

- $100-500$

- $500-1000$

- $1000-10000$

- $10,000-100,000$

- $100,000-500,000$

- $500,000-1,000,000$

- Above $1,000,000$

Q7 Does your school participate in the Title - 1 program?

- Yes

- No

Q8 If you answered "No" to the previous question, is your school eligible to participate in the Title - 1 program?

- Yes

- No

- I do not know

Q9 Does your school participate in CyberPatriot - The National Youth Cyber Education Program?

- Yes 
- No

Q10 If you answered "Yes" to the previous question, for how many years has your school participated in CyberPatriot?

- 1

- $2-3$

- $4-6$

- More than 6

Q11 To what extent do you rate yourself as knowledgeable in Cybersecurity?

- Extremely knowledgeable

- Very knowledgeable

- Moderately knowledgeable

- Slightly knowledgeable

- Not knowledgeable at all

Q12 To what extent are your students knowledgeable in Cybersecurity?

- Extremely knowledgeable

- Very knowledgeable

- Moderately knowledgeable

- Slightly knowledgeable

- Not knowledgeable at all

Q13 How interested are your students in learning about Cybersecurity topics?

- Extremely interested

- Very interested

- Moderately interested

- Slightly interested

- Not interested at all

Q14 My school employs active hands-on learning to teach Cybersecurity to the students

- Strongly agree

- Somewhat agree

- Neither agree nor disagree

- Somewhat disagree

- Strongly disagree

Q15 My school is actively involved in the professional development of teachers, focused on STEM education

- Strongly agree

- Somewhat agree

- Neither agree nor disagree

- Somewhat disagree

- Strongly disagree

Q16 High School students are more likely to be exposed to age-appropriate topics in Cybersecurity compared to Elementary and Middle School
- Strongly agree

- Somewhat agree

- Neither agree nor disagree

- Somewhat disagree

- Strongly disagree

Q17 Cybersecurity is offered in my school in the following ways. Select all that apply.

- Incorporated into the curriculum

- Offered as an extracurricular activity

- Offered as a competition

- Offered as a summer camp

- Other

Q18 My community has organizations/companies that employ cybersecurity specialists.

- Strongly agree

- Somewhat agree

- Neither agree nor disagree

- Somewhat disagree

- Strongly disagree

Q19 Interest to learn or engage in activities fostering Cybersecurity education has significantly decreased during the pandemic.

- Strongly agree

- Somewhat agree

- Neither agree nor disagree

- Somewhat disagree

- Strongly disagree

Q20 My school offers other STEM based programs (excluding Cybersecurity based programs) in some capacity (either as a camp, club, competition or as a standalone course).

- Strongly agree

- Somewhat agree

- Neither agree nor disagree

- Somewhat disagree

- Strongly disagree 